\title{
AMOSTRAGEM GEOLÓGICA NA PESQUISA MINERAL
}

\author{
Alberto G. Figueiredo Jr. \& Isa Brehme
}

Received August 24, 2001 / Accepted December 05, 2001

\begin{abstract}
Este artigo descreve o funcionamento e emprego de equipamentos de amostragem de sedimento ou rocha no fundo marinho com emprego na prospecção mineral. Os equipamentos são classificados de acordo com suas propriedades de amostragens. Desenhos e fotos ilustram os equipamentos, enquanto tabelas fornecem suas principais características.
\end{abstract}

Palavras chave: Recursos minerais; Equipamentos de amostragem; Equipamentos de sondagem; Amostradores de sedimento.

GEOLOGICAL SAMPLING IN MINERAL EXPLORATION - This paper describes the functioning and application of sampling equipments for sediments and rocks of the ocean bottom used on mineral prospecting. Equipments are classified accordingly to their sampling properties. Equipments are shown on drawings and photos and tables give their main characteristics.

Key words: Mineral resources; Sampling equipment; Sediment sampler; Sediment corer.

Universidade Federal Fluminense

Departamento de Geologia/Laboratório de Geologia Marinha - LAGEMAR

Av. Litorânea, s.n., Gragoatá, Niterói, RJ, 24210-340

Telefone e fax: (5521)2719-4241

Email: alberto@igeo.uff.br,www.igeo.uff.br/lagemar

\section{INTRODUÇÃO}

A investigação do fundo oceânico para prospecção de bens minerais pode ser realizada de forma direta ou indireta. As formas indiretas são aquelas com as quais pode-se obter informações do fundo marinho sem, no entanto ter em mãos amostra do material, como por exemplo, a sísmica, a sonografia e batimetria. Tendo em vista que os métodos indiretos são mais expeditos e podem cobrir grandes áreas em pouco tempo, estes, de maneira geral, são os primeiros a serem aplicados e servem para orientação da amostragem geológica que por sua vez é um método direto de investigação do fundo marinho.

A amostragem geológica do fundo marinho a primeira vista parece trivial, mas quando considerados os diversos fatores que podem influenciar uma amostragem, incluindo profundidade, velocidade de correntes de fundo, estado do mar e natureza do fundo, é fundamental a adoção de equipamentos apropriados. Além desses fatores, é importante que a amostra seja representativa. Ao longo do tempo os equipamentos de amostragem geológica vem sendo desenvolvidos e aperfeiçoados visando atender estas questões. Uma das técnicas originais de amostragem de fundo denominada tensa consistia em um peso com uma área preenchida por sabão que ao tocar o fundo grudava o sedimento. É fácil imaginar que, ao ser erguido do fundo oceânico até a embarcação, a amostra era lavada e parte do sedimento perdida, assim a representatividade não podia ser considerada.

Junto com o desenvolvimento dos equipamentos, foram também desenvolvidos cabos de aço de grande resistência e leveza que permitem atingir profundidades de até 6.000 metros. Alguns desses cabos atualmente são trançados junto com 
cabos elétricos e de fibra ótica, possibilitando, por exemplo, fotografar o fundo ou mesmo inspecionar e direcionar o amostrador antes da amostragem. A grande maioria dos equipamentos foi desenvolvida pelos próprios cientistas que os utilizavam e por esta razão é comum o equipamento ter o nome de seus inventores.

Além da questão do volume e da representatividade da amostra, uma das áreas que começa a ser tratada por aqueles que querem entender com mais detalhe o ambiente marinho, é a questão de análise do dado in situ. Sabemos que a pressão hidrostática, temperatura ambiente, velocidades de correntes e uma série de outros fatores podem ter influência nas análises. Assim, por exemplo, medidas geotécnicas, medidas geofísicas, consumo de oxigênio e trocas iônicas entre a coluna d'água e o sedimento, já tem sido realizadas no sedimento quando ainda no fundo marinho.

Os recursos minerais marinhos podem ocorrer distribuídos em superfície ou sub-superfície e a avaliação dos depósitos depende do emprego de amostradores que possam fazer amostragens representativas.

Este artigo não tem pretensão de cobrir todos os equipamentos de amostragem de fundo existentes, por serem numerosos e estarem em constante desenvolvimento. Serão tratados os equipamentos mais usuais para avaliação do potencial mineral e aqueles que representam avanço tecnológico na amostragem e coleta de dados do fundo marinho em sedimentos não consolidados. As amostragens com perfuração de sondas rotativa para hidrocarbonetos não serão tratadas neste artigo.

\section{AMOSTRAGEM DE FUNDO}

A amostragem de fundo é realizada com o propósito de definir a natureza do fundo, a quantidade de minerais ou realizar análises de detalhe. Portanto é fundamental que a amostra seja integral e representativa para que os resultados das análises sejam válidos.

A definição dos pontos de amostragens deve levar em conta além do espaçamento entre amostras, se possível os dados de batimetria, sísmica rasa de alta definição e imagens de sonar. Estes dados indiretos permitem uma avaliação da variabilidade da topografia, da natureza do fundo e da existência de trapas em sub-fundo, dando subsídios a uma melhor definição de onde realizar amostragem, além de informação sobre até onde se estende o domínio daquela determinada litogia ou concentração mineral. Outros dados indispensáveis são posicionamento geográfico, profundidade, dia, hora, equipamento coletor e uma breve descrição da amostra e das condições de amostragens. Todas estas informações devem estar contidas em uma ficha a ser preenchida no momento da coleta para facilitar o processamento do dado e esclarecer dúvidas futuras caso existam. Há uma variedade enorme de fichas e cada uma apropriada para um determinado tipo de equipamento.

\section{TIPOS DE AMOSTRADORES}

Para facilitar a visualização dos tipos de equipamentos e suas aplicações, foi elaborada uma classificação dos diversos tipos de amostradores de fundo conforme indicado naTtabela 1.

São classificadas como superficiais as amostragens que não passam de $30 \mathrm{~cm}$ de profundidade e englobam os equipamentos tipo busca-fundo e dragas de arrasto. Estas amostragens por sua vez podem ser classificadas em amostras pontuais que compreendem uma área amostrada aproximadamente do tamanho do equipamento enquanto que as amostras não pontuais são aquelas em que o equipamento é arrastado no fundo por uma determinada distância e os sedimentos coletados podem representar mais de uma fácies sedimentar. Um resumo de suas principais características está na Tabela 2

As amostragens sub-superficiais envolvem a coleta de sedimentos desde a superfície do fundo marinho até dezenas de metros e para isto são empregados as amostradores caixa e os testemunhadores. As principais características dos testemunhadores estão resumidas naTabela 3 .

A seguir são apresentados os principais equipamentos utilizados em amostragem de fundo, os quais têm sido reproduzidos ao longo do tempo em diversos países, em diferentes tamanhos e com adaptações. As características aqui apontadas são, portanto genéricas para aquele tipo de equipamento. 
AMOSTRADORES SUPERFICIAIS NÃO PONTUAIS

Os amostradores não pontuais são aqueles que são arrastados no fundo marinhos por uma determinada distância coletando material do fundo (Zembruscki \& Felipe1978). Caso haja uma variação de fácies o amostrador irá coletar uma amostra composta. Normalmente este tipo de amostrador é utilizado para fornecer uma informação que não necessite muita precisão dos dados e sua aplicação é usual na coleta de sedimento, dragagem de rochas, nos estudos de levantamento expeditos e de biota de fundo. A estes amostradores é aplicado o nome de draga cujos principais representantes são draga de Gibbs, draga de correntes e draga biológica (Fig 1).

\section{Draga de Gibbs.}

Trata-se de um dos instrumentos mais simples para amostragem e, todavia bem eficaz. É constituída por um tubo de metal com diâmetro variável, onde em uma das extremidades está preso um saco de tecido para recolher a amostra e na outra, que tem a borda cortante, é fixo o cabo de arrasto (Fig. 1a). Para se fazer uma dragagem com um ângulo de arrasto suficiente para não levantar inadvertidamente o equipamento do fundo, é importante que o comprimento do cabo seja pelo menos 2,5 vezes a profundidade. Após alguns minutos de arrasto o equipamento é içado a bordo e o sedimento recolhido do saco. Dependendo de sua dimensão, este equipamento pode ser manuseado manualmente de uma pequena embarcação. Quando utilizado em águas mais profundas, deve ser dimensionado com mais peso e caso necessário, pesos adicionais podem ser colocados no cabo de reboque avante da draga. Um dos problemas deste equipamento é o efeito de lavagem do sedimento durante o resgate e outro problema é a coleta de sedimento misturado caso o equipamento se arraste sobre mais de uma fácies sedimentar.

\section{Draga retangular ou draga biológica.}

A draga retangular ou também chamada biológica tem um formato retangular com uma borda cortante $\mathrm{e}$ seu corpo formado por uma armação de metal com tela (Fig. 1b). O seu interior é revestido por um tecido para armazenar o sedimento. $\mathrm{O}$ seu arrasto é feito por duas hastes flexionadas por dobradiças presas à borda cortante. As hastes são presas duas pontas de cabo que se unem ao cabo principal. Da mesma forma que na draga Gibbs para se fazer uma dragagem sem levantar inadvertidamente o equipamento do fundo, é importante que o comprimento do cabo seja pelo menos 2,5 vezes a profundidade.

É comum a perda de equipamentos de arrasto de fundo quando estes se prendem a obstáculos de fundo. Para diminuir esta perda das dragas, uma das pontas do cabo é ligado a haste com um elo de segurança que se rompe no caso de muita tensão. $\mathrm{O}$ rompimento de apenas uma ponta de tração fará com que a draga rodopie em volta do obstáculo de fundo libertando-se. Para atingir maiores profundidades pesos adicionais podem ser colocados no cabo a vante da draga.

\section{Draga de rochas}

A draga de rocha ou draga de corrente é utilizada para dragar rochas de formações rochosas da cordilheira mesoceânica, platôs e montes submarinos. Por se tratar de uma draga que sofre alto impacto com o fundo e com grande chance de perda, ela deve ser de material bem resistente e de baixo custo. $\mathrm{O}$ formato mais comum deste tipo de draga tem uma boca retangular de bordas cortantes e algumas vezes providas de dentes que ajudam a arrancar parte da rocha. A parte posterior que abriga a amostra é normalmente feita de uma malha de correntes. Da mesma forma que nas outras operações de dragagem, o comprimento do cabo lançado ao mar deve ser de 2,5 vezes a profundidade. Por se tratar de uma amostragem que colocará muita tensão no cabo de arrasto, é importante que os operadores se mantenham alerta e as áreas de risco livres. Uma fotografia de uma draga de rochas é apresentado na 1c.

\section{AMOSTRADORES PONTUAIS}

SUPERFICIAIS

Os amostradores pontuais de superfície ou busca-fundo (Fig. 2) são geralmente equipamentos 


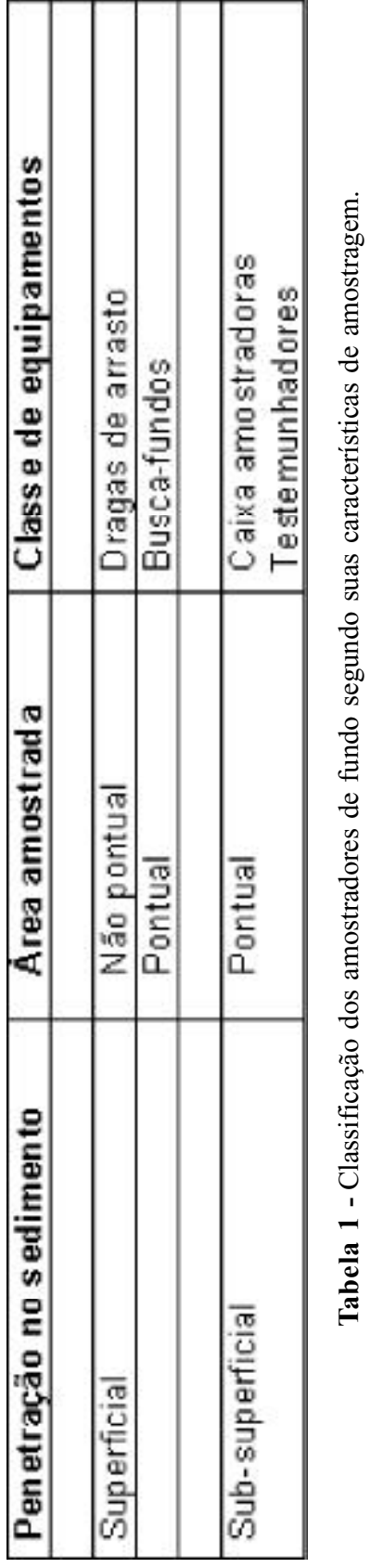

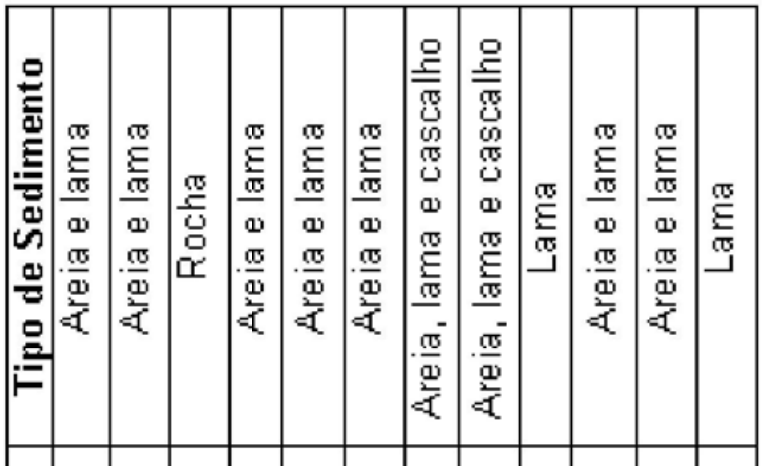

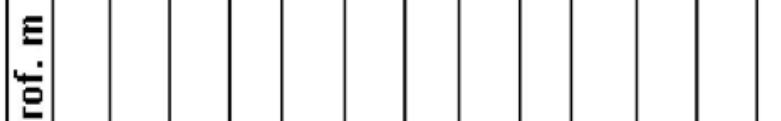

告

绐 㗁吅

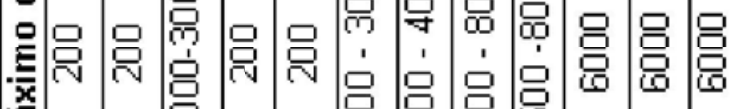
商

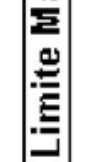

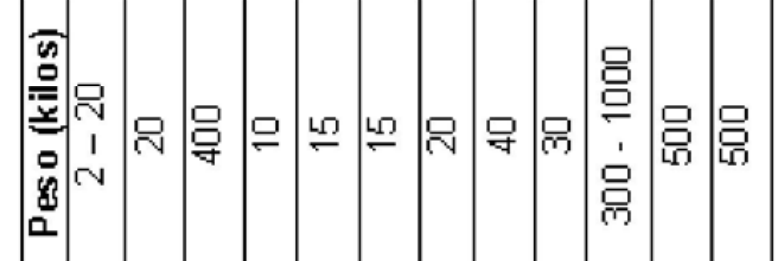

牙

Lip

(1)

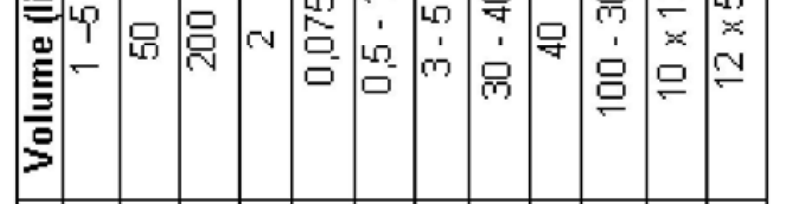

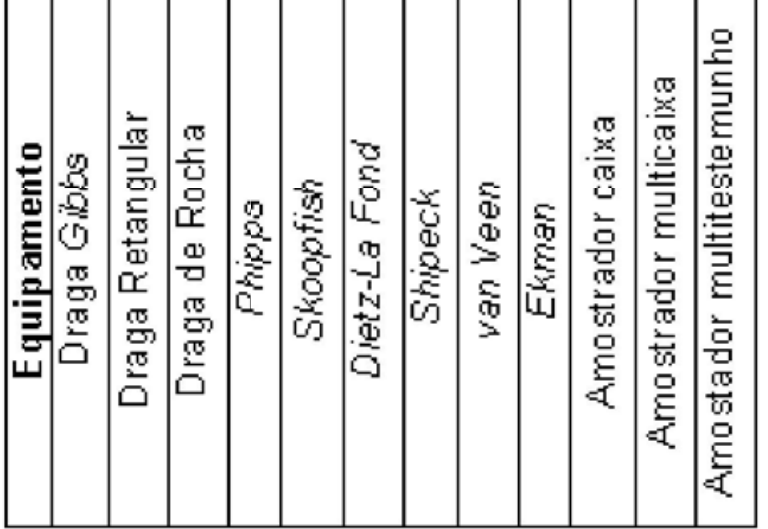

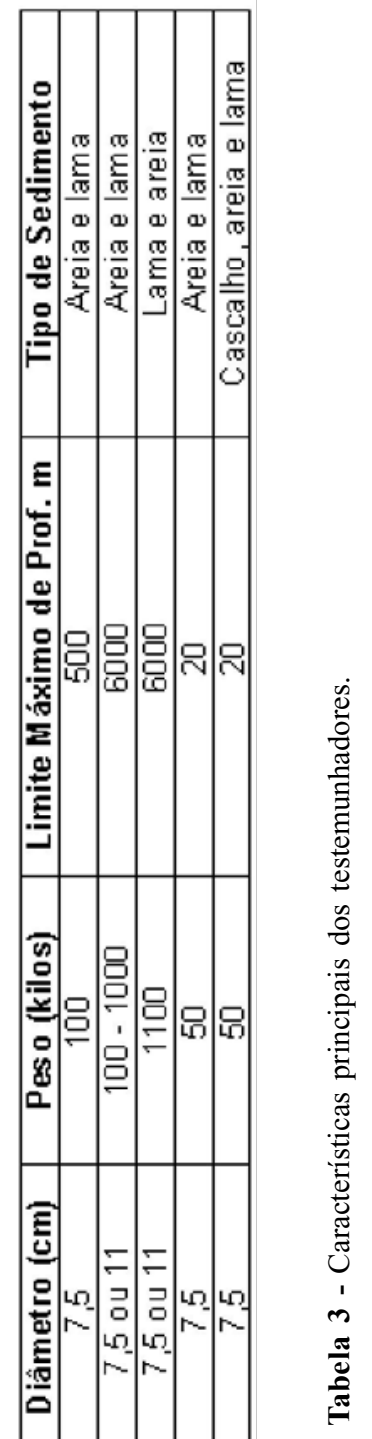

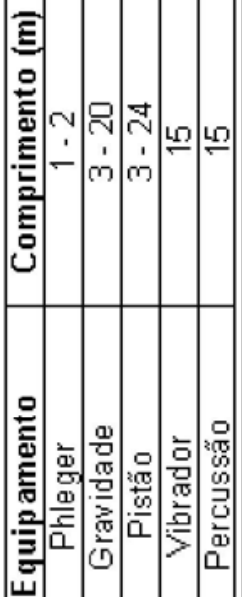



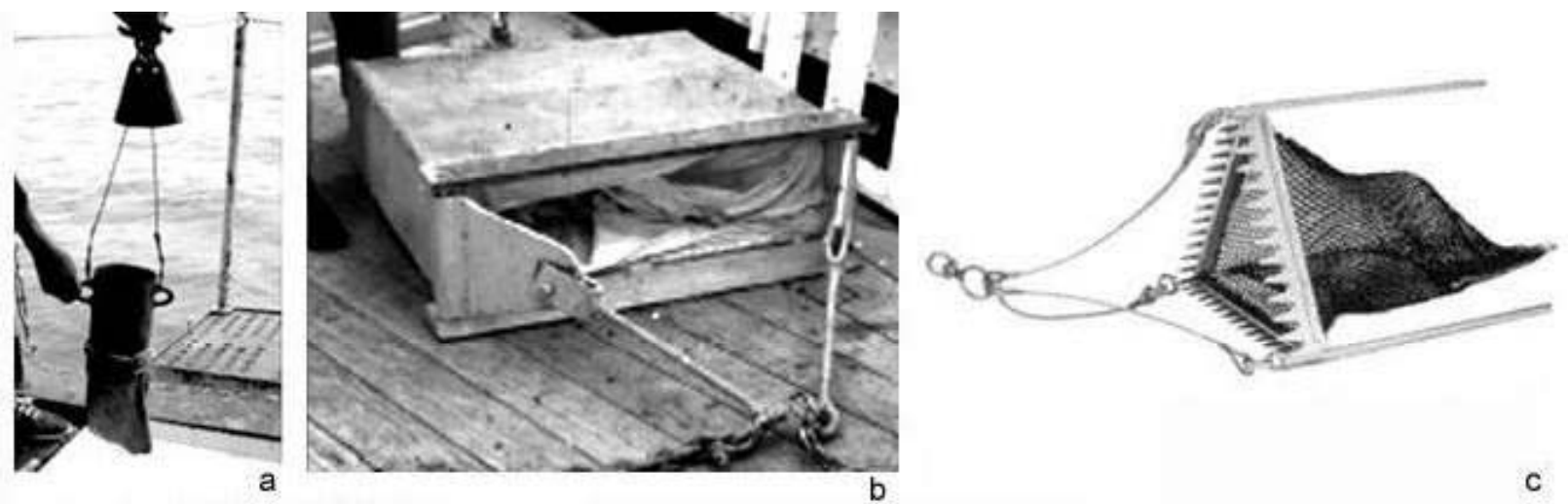

Figura 1 - Dragas: a - Draga Gibbs; b - Draga retangular; c - Draga de rochas.

leves, podendo ser utilizados em embarcações pequenas, e permitem rapidez entre uma amostragem e outra. Junto com a geofísica eles são ideais para conhecer o fundo antes de enviar equipamentos que demandem mais tempo de operação e que sejam mais valiosos como, por exemplo, um testemunhador ou um amostrador caixa em embarcações de maior porte. Dentre os amostradores pontuais somente o Phipps e Skoopfish são utilizados com a embarcação em movimento.

\section{Phipps}

Este é um amostrador superficial pontual que é utilizado com o barco ou navio em movimento (Ellis 1973, Kowsman et al. 1983). Ele tem o formato de um tubo tendo em um lado uma borda cortante e no outro um saco de tecido para armazenar o sedimento (Fig. 2a). O tubo tem um sistema de tração reversível em que, para descer ao fundo, com o navio em movimento, o equipamento é tracionado por um ponto na parte posterior e, auxiliado por aletas também na parte posterior, o equipamento é direcionando ao fundo. Ao tocar o fundo rompe-se um elo de barbante que prende o cabo de tração a parte posterior e o equipamento passa a ser rebocado pela parte dianteira e assim com tendência a subir. Uma das desvantagens deste equipamento é o processo de lavagem que a amostra sofre durante a recuperação do equipamento. O equipamento é utilizado com freqüência junto com a perfilagem de sonar de varredura lateral, permitindo que o fundo seja amostrado sem interromper a navegação com o navio a 3 ou 4 nós de velocidade. Os resultados são uma ajuda na interpretação dos registros.

\section{Skoopfish}

É um equipamento semelhante em forma e funcionamento ao amostrador Phipps. Possui, porém uma placa articulada que fecha a extremidade aberta após o equipamento tocar o fundo (Emery \& Champion 1948). O recipiente na extremidade dianteira de $4 \mathrm{~cm}$ de diâmetro, tem capacidade de amostragem de $75 \mathrm{~cm}^{3}$ e é facilmente introduzido e removido com a amostra para posterior análise. Funciona muito bem em profundidades de até $200 \mathrm{~m}$ com a embarcação em movimento. Na figura $2 b$ pode ser visto o equipamento e o tubo de coleta.

\section{Dietz-La Fond}

É um equipamento prático de pequeno porte para ser utilizado em pequenas profundidades incluindo rios, lagos e plataforma continental (La Fond \& Dietz 1948). Ele tem uma estrutura alongada com duas conchas na base e uma aleta verticalizadora na parte posterior (Fig. 2c). As conchas que abocanham o sedimento são impulsionadas por um peso que desliza ao longo de um cursor. O equipamento desce ao fundo com as conchas abertas e travadas por uma barra transversal, que assim que toca o fundo, libera as conchas para abocanhar o fundo.

\section{Shipeck}

É um busca-fundo com um volume e peso maior que do Dietz-La Fond e princípio de funcionamento diferente. O Shipeck tem um formato de um semicilindro e seu sistema de fechamento é acionado por uma poderosa mola de aço (Fig. 2d). Quando armado para descer ao fundo o Shipeck tem forma 
de um semicilindro armazenado dentro da estrutura do equipamento. Assim que toca o fundo um peso na parte superior do equipamento desliza por um cursor, bate em uma trava que libera o semicilindro interno que é impulsionado pela mola. O semicilindro corta o sedimento e armazena-o dentro do equipamento.

Uma característica importante deste equipamento é que, dependendo do tipo de sedimento, a superfície do sedimento pode ser preservada. Outra característica importante é que o semicilindro pode ser substituído por outro limpo enquanto aquele com sedimento é processado e assim ganha-se tempo na amostragem. $\mathrm{O}$ fato de o Shipeck ter uma mola muito forte faz com que sedimentos semiconsolidados e crostas possam também ser amostrados. Devido a esta mola forte deve ser manuseado com cuidado.

\section{van Veen}

É um equipamento de funcionamento simples, robusto que, dependendo de seu tamanho, pode pegar grande volume de sedimentos. Ele é constituído de duas conchas articuladas por uma dobradiça através de duas barras cruzadas presas ao cabo de aço que vai até a embarcação (Fig. 2e). As conchas se mantêm abertas por um sistema de trava que é liberado assim que o equipamento toca o fundo. $\mathrm{O}$ recolhimento do cabo faz com que as conchas se fechem apanhando o sedimento. Por não ter vedação perfeita, pode ocorrer lavagem de amostra.

\section{Ekman}

É um equipamento em formato de caixa, semelhante ao amostrador caixa descritas a seguir com a diferença no sistema de fechamento e acesso ao sedimento amostrado. $\mathrm{O}$ amostrador de Ekman (Fig. 2f) desce ao fundo com as tampas superiores e também as duas mandíbulas em forma de segmento de cilindro aberto. Assim que equipamento toca o fundo é liberada a tensão que prende uma trava na parte superior do equipamento e as mandíbulas são impulsionadas por duas potentes molas de aço além das tampas superiores serem fechadas. Uma das vantagens deste amostrador é que a superfície de interface água-sedimento é preservada e assim pode ser observada e sub-amostrada.

\section{AMOSTRADORES PONTUAIS DE SUB- SUPERFÍCIE}

Os amostradores pontuais de sub-superfície são aqueles que amostram desde a interface águasedimento de fundo até dezenas de metros. São equipamentos mais pesados e têm como principal propriedade preservar a estratigrafia dos sedimentos. Dentro desta classificação de sub-superficiais temos duas categorias, os amostradores caixa que recuperam um bloco de sedimento de pequeno comprimento (Fig. 2g, h, I) e os testemunhadores que podem recuperar longas seções de sedimento (Fig. 3). Os testemunhadores por sua vez podem ser divididos em "com pistão" e "sem pistão", usualmente também chamado de testemunhador a "gravidade". Duas outras classes de testemunhadores são os testemunhadores com "vibrador" e testemunhadores com "martelete de impacto". As principais características estão resumidas na tabela 3 .

\section{Caixa amostradora}

A caixa amostradora, do inglês box-corer, foi desenvolvida de forma a ser possível amostrar um bloco de sedimentos que pudesse posteriormente ser secionado em diversas direções. Ela foi desenvolvida por Reineck (1963) para o estudo de estruturas primárias e biológicas nos sedimentos do Mar do Norte e hoje tem um emprego universal desde as regiões inter-marés até o oceano profundo.

A caixa amostradora tem formato de uma caixa que é inserida em uma estrutura alongada e tem um braço articulado com uma lâmina que fecha a base no momento de retirada da mesma do fundo. A estrutura do equipamento possui também uma armação a sua volta que serve para garantir a verticalização da caixa amostradora ao tocar o fundo (Fig. 2g). A caixa amostradora desce ao fundo com a tampa superior e a lâmina de fechamento aberta até que o equipamento se enterrar no sedimento. Neste momento fecha-se a tampa superior e a medida que o equipamento é içado, o braço articulado gira em torno de um pivô e a lâmina de fechamento corta o sedimento até fechar totalmente a base da caixa. Uma vez a bordo, a caixa amostradora é retirada da 


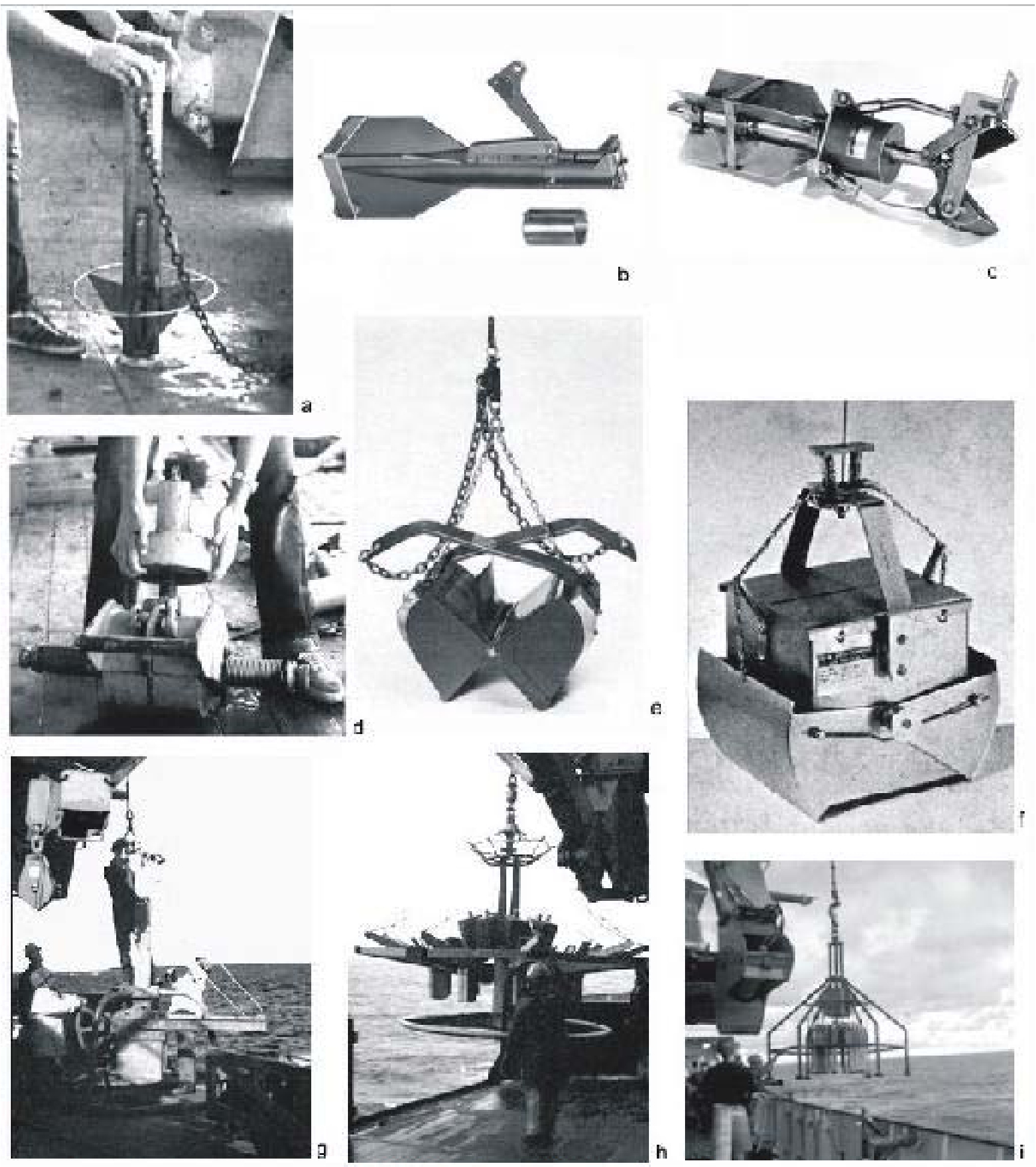

Figura 2 - Busca-fundo

a - Amostrador Phipps; b - Amostrador Skoopfish; c- Amopstrador Dietz-La Fond; d - Amostrador Shipeck; e - Amostrador van Veen; f - Amostrador Ekman; g - Amostrador caixa; h - Amostrador multi-caixa; i - Amostrador multi-testemunhador. 


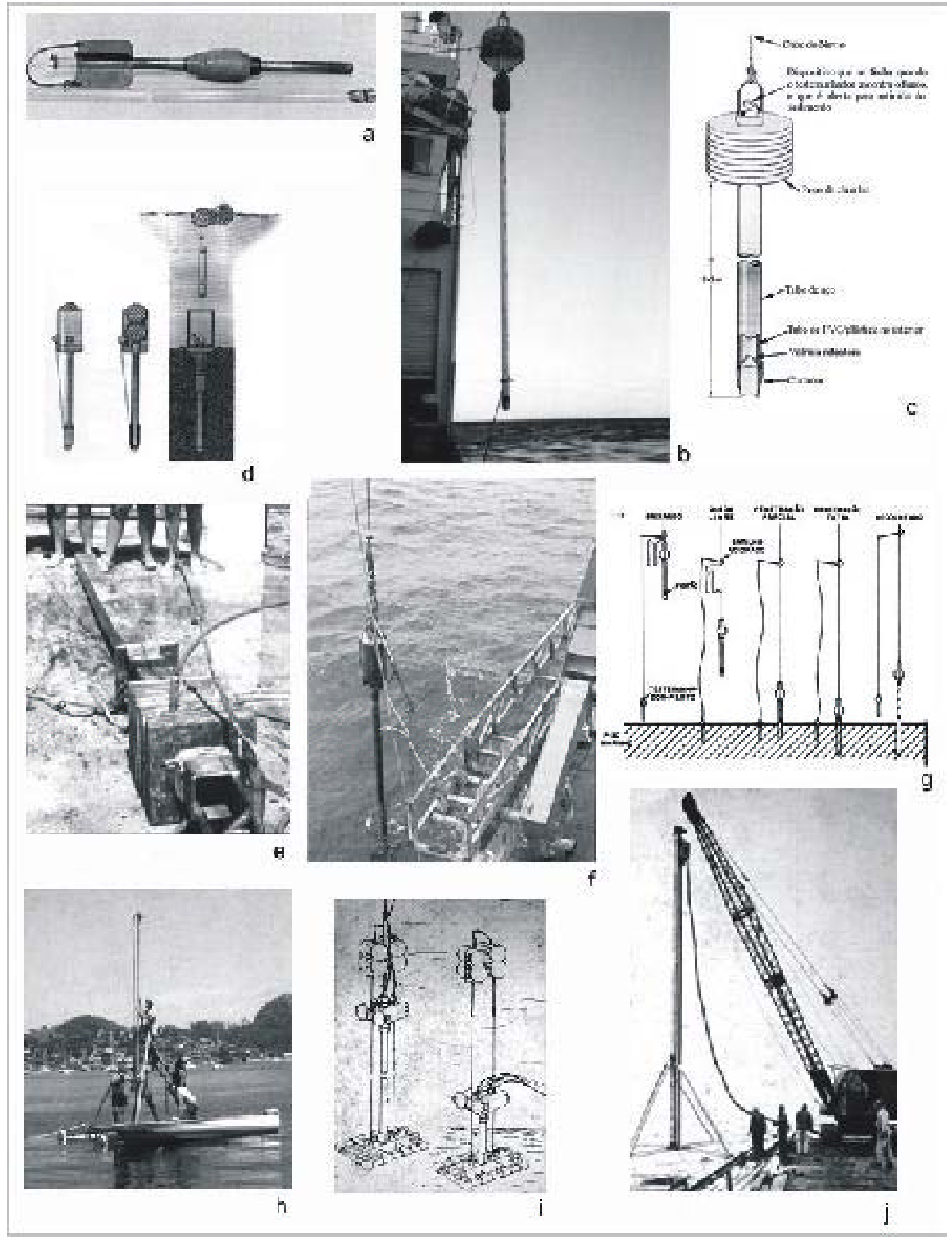

Figura 3 - Testemunhadores

a - Testemunhador Phleger; b - Testemunhador a gravidade; c - Esquema das partes de um testemunhador a gravidade; $\mathrm{d}$ -

Testemunhador de queda livre; e - Testemunhador caixa; f - Lançamento de um testemunhador a pistão; $g$ - Esquema de funcionamento de um testemunhador a pistão; $\mathrm{h}$ - Testemunhador a vibração em ação em águas rasas; $\mathrm{i}$ - Testemunhador a vibração submersível; $\mathrm{j}$ Testemunhador a percussão Alpine. 
estrutura e iniciam-se os procedimentos de subamostragem. Uma das vantagens da caixa amostradora é que uma das laterais da caixa pode ser removida e assim o bloco de sedimento pode ser secionado em diversas direções e intervalos.

\section{Multi-amostradores}

O sistema do amostrador caixa é utilizado em amostragem múltipla com caixas amostradoras estreitas arranjadas em círculo, permitindo a amostragem de uma área maior (Fig. 2h). O equipamento tem bom funcionamento em sedimentos lamosos a arenosos em qualquer profundidade, mas devido ao tamanho do equipamento, necessita de navio com guincho. O mesmo acontece com o multitestemunhador (multi-corer), onde em lugar de caixas são utilizados tubos de PVC ou acrílico de $1 \mathrm{~m}$ de comprimento com dispositivos de fechamento dos topos e das bases dos tubos (Fig. 2i). Os tubos descem ao fundo projetados à frente da estrutura, com a tampa superior aberta, bem como a inferior que é articulada por um braço móvel. Ao penetrar no sedimento as tampas superiores são fechadas por uma mola, enquanto as tampas inferiores cortam o sedimento até chegarem a base dos tubos. Devido à espessura da tampa da base o multi-testemunhador só trabalha bem em sedimentos lamosos inconsolidados. Também neste amostrador a preservação tanto da água como da interface sedimento-água é excelente. Após a retirada dos tubos da estrutura, estes são colocados em um suporte que viabilize a saída do sedimento pelo topo, à medida que o tubo de acrílico é abaixado. Este sistema permite a sub-amostragem do sedimento, fatiando-o em camadas centimétricas e com isto a obtenção de uma estratigrafia detalhada. Outro ponto interessante deste sistema é a disponibilidade de diversas amostras semelhantes, o que possibilita a correlação entre diversos tipos de análises.

\section{TESTEMUNHADOR À GRAVIDADE}

Os testemunhadores à gravidade são os dispositivos mais simples dentre os testemunhadores. O testemunhador Phleger (Fig. 3a), hoje ainda utilizado como peso piloto em testemunadores a pistão, é um testemunhador pequeno e prático para obter testemunhos curtos até manualmente de embarcações pequenas. Constitui-se de um tubo com um peso na parte posterior onde se prende o cabo de sustentação e uma ponta cortante que penetra no sedimento. Na parte interna possui um tubo de PVC de 2,5 a 6,5 cm de diâmetro com um dispositivo de lâminas na extremidade inferior que impedem a perda do material amostrado.

Com o tempo este pequeno testemunhador foi melhorado (Fig. 3b). O tubo, normalmente chamado de barrilete, pode ser de aço ou PVC rígido com diâmetro usualmente de 7,5 ou $11 \mathrm{~cm}$ e em seções conectáveis de $3 \mathrm{~m}$ de comprimento. Quando se utiliza o barrilete de aço, normalmente se utiliza um tubo interno de PVC para armazenar o sedimento. $\mathrm{Na}$ parte superior o peso de 1,5 toneladas ajuda na penetração. Alguns destes testemunhadores possuem uma válvula na parte superior do tubo e outra na parte inferior. A válvula no topo evita a entrada de água e assim a lavagem do sedimento, enquanto a válvula inferior, chamada de "válvula retentora" ou "aranha" impede a saída do sedimento durante a retirada do fundo. Uma das partes importantes do testemunhador é o cortador que vai preso na ponta do tubo (Fig. $3 c)$. Este cortador deve ser dimensionado para ter um perfil que cause o menor atrito possível durante a penetração no sedimento e assim permita uma boa penetração com bastante recuperação. Este tipo de testemunhador é usualmente descido ao fundo com o guincho sob controle a $1-1,5 \mathrm{~m} / \mathrm{s}$. Quando faltam poucos metros o guincho pode ser totalmente liberado para que com a descida mais rápida haja maior penetração. Também pode ser utilizado um sistema de alavanca (Hvorslev \& Stetson, 1946) que consiste de um braço disparador que funciona em um sistema de equilíbrio baseado em um binário de forças onde o testemunhador é preso pela alça no braço menor enquanto o peso disparador ou peso piloto é preso no braço maior. Desta forma, o testemunhador que pode pesar até 1 tonelada é equilibrado por um peso de $100 \mathrm{~kg}$. Para a operação de testemunhagem, o cabo que vem do guincho é passado no braço disparador que prende o cabo e ao mesmo tempo sustenta o testemunhador por uma alça. Após a passagem pelo braço disparador o cabo forma um seio que corresponde ao tamanho da queda livre e é 
fixo na alça do testemunhador. Tendo em vista que o cabo que prende o peso piloto é maior que o comprimento do testemunhador, este segue na frente e tocará o fundo primeiro. Ao tocar o fundo o binário de força é desequilibrado e o testemunhador é liberado e cai em queda livre penetrando no sedimento.

O testemunhador sem cabo nem guincho é um equipamento de testemunhagem à gravidade com queda livre (Moore, 1961). Ele consiste de um tubo leve, fixado em dispositivos flutuantes e que vai ao fundo marinho dentro de um envoltório pesado, descartável (Fig. 3d). É lançado livre na água e impulsionado pelo seu peso penetra no fundo. O tubo com os flutuadores é liberado em seguida e volta à superfície da água com os sedimentos recuperados. É um sistema prático para coleta rápida de testemunhos curtos em águas rasas.

\section{TESTEMUNHADOR CAIXA}

O testemunhador caixa (kasten corer) é um testemunhador a gravidade de seção quadrada de 30 x $30 \mathrm{~cm}$ de $3 \mathrm{~m}$ ou mais de comprimento feito em aço inox (Fig. 3e). Na parte posterior são colocadas diversas placas de chumbo para dar peso suficiente para a penetração do testemunhador no sedimento. Na parte anterior é colocada uma ponteira com bordas cortantes e internamente uma válvula que permite a entrada do sedimento, mas impede sua saída. Durante a coleta, para a verticalização do testemunhador é colocado um peso guia próximo a parte anterior preso por dois cabos à parte posterior. A medida que o testemunhador penetra no sedimento este peso permanece na superfície. Uma das características deste testemunhador é que a seção quadrada é formada por uma parte em perfil "U" e a outra uma tampa que é aparafusada no perfil em " $U$ ". Após a coleta do testemunho esta tampa é retirada permitindo o acesso à seção completa do testemunho para sub-amostragens, fotografias e outros estudos.

\section{TESTEMUNHADORES À PISTÃO}

O testemunhador com pistão, inventado por Kullenberg (1947) (Fig. 3f) é sempre utilizado com o sistema de alavanca disparadora para propiciar queda livre. Os testemunhadores com pistão são muito semelhantes aos testemunhadores à gravidade possuem, porém um pistão que corre dentro do tubo de PVC e que tem a função de impedir fricção severa e encurtamento da seção sedimentar. Durante a operação de testemunhagem este pistão fica logo após a válvula retentora até que o seio de cabo na alavanca disparadora seja totalmente desfeito e isto corresponde ao momento que o cortador toca o fundo. A partir daí, o testemunhador penetra no sedimento enquanto o pistão mantém-se estático. A figura $3 \mathrm{~g}$ ilustra o funcionamento do testemunhador com pistão. Um problema que ocorre neste tipo de testemunhagem é quando o testemunhador não é preenchido completamente com sedimentos. Quando o testemunhador é içado pelo pistão o sedimento pode ser sugado para cima ou pode ocorrer implosão do tubo interno. Procurou-se contornar este problema utilizando um pistão rompível em que uma parte permanece sobre o sedimento e a outra superior iça o testemunhador.

Silva \& Hollister (1973) desenvolveram um testemunhador a pistão gigante com diâmetro de 14 cm (11,5 tubo interno) e peso de 5 toneladas que pode recuperar 20-40 m de sedimentos. Devido as suas dimensões só pode ser utilizado em navios maiores com guincho adequado.

Atualmente o testemunhador com pistão é utilizado principalmente em sedimentos lamosos inconsolidados, enquanto o testemunhados à gravidade tem uma recuperação melhor em sedimentos arenosos ou endurecidos.

\section{TESTEMUNHADORES À VIBRAÇÃO}

Os testemunhadores a vibração baseiam-se no princípio da liquefação do sedimento pela vibração(Lanesky et al., 1979). O vibrador mais comum é o utilizado em construções civis para liquefazer o concreto para a expulsão das bolhas de ar e constitui-se de um motor a gasolina, ligado ao um cabo coaxial que tem um eixo excêntrico na ponta. Esta ponta, que é a parte vibrante, deve ser firmemente presa ao testemunhador e este por sua vez tem que ser de metal para melhor conduzir as vibrações. Ao vibrar o tubo liquefaz o sedimento a sua volta permitindo que o tubo penetre no sedimento com facilidade. Os tubos mais freqüentemente utilizados 
tem sido os de alumínio com diâmetro de $7.5 \mathrm{~cm}$, parede com $2 \mathrm{~mm}$ de espessura e $9 \mathrm{~m}$ de comprimento. Este testemunhador a vibração é montado em uma torre de sustentação e pode ser utilizado em terra, em água rasa (Fig. 3h) e até em mar profundo (Fig. 3i).

\section{TESTEMUNHADORES A PERCUSSÃO}

Os testemunhadores à percussão são acionados por impactos de alta freqüência sobre o tubo que penetra no solo. Este sistema pode tanto funcionar no fundo marinho bem como fora d'água e em ambos os casos o testemunhador é sustentado na vertical por uma torre. A percussão na parte posterior do tubo pode ser produzida por martelete acionado por ar comprimido. O tubo deve ser resistente e de parede fina para que o atrito com o sedimento seja o menor possível. A utilização de um cortador na base pode facilitar a penetração e uma válvula retentora deve ser utilizada em sedimentos com muita água. Também este testemunhador pode ser utilizado submerso ou fora d'água. A figura $2 \mathrm{j}$ apresenta o testemunhador a percussão Alpine.

\section{AMOSTRADORES DE SEDIMENTO EM SUSPENSÃO}

Os amostradores de sedimento em suspensão chamados de "armadilhas de sedimento" foram desenhados para capturar o sedimento em suspensão. Existem dois tipos básicos: um deles mais simples, "armadilha tubular de sedimento", que captura todo o sedimento sem separar o período de amostragem e a "armadilha temporizada de sedimento" que captura o sedimento por período de tempo e o armazena separadamente. As principais características destes amostradores estão resumidas na tabela 4 .

A armadilha tubular de sedimentos é constituída de uma estrutura simples onde um tubo de PVC com uma das extremidades fechada é enterrado no sedimento. A outra extremidade fica aberta e coleta o sedimento que desce na coluna d'água. Existem também tubos que tem aberturas nas laterais para captura de sedimentos que estejam sendo transportados por correntes. Caso queira se amostrar sedimento de tração de fundo, o tubo deve ser enterrado até que sua borda fique próxima da superfície do sedimento.

A armadilha temporizada de sedimento tem forma de um funil com 1 metro de boca e 2 de altura. Na sua base são colocados uma série de frascos (12 - 24) em um tambor que gira a um tempo prédeterminado. Estas armadilhas são geralmente utilizadas em oceano profundo e podem ficar até 3 anos no fundo antes de serem recuperadas. Para que haja conservação da matéria orgânica que cai na armadilha, os frascos contêm uma solução conservante. Normalmente este tipo de armadilha é colocada em série a diversas profundidades da coluna d'água e seguras por um cabo que pode ser liberado do fundo por meio de ondas acústicas. Uma outra forma de utilizar estas armadilhas é colocando-as à deriva acompanhadas por um barco ou por rastreamento com satélite. Os dados das armadilhas servem para avaliar a razão de sedimentação.

\section{AMOSTRADORES DE DADOS in situ}

Diversas medidas realizadas em laboratório divergem das medidas realizadas in situ em função de parâmetros que dependem da pressão hidrostática, da preservação do arranjo das camadas e não perturbação da biota. Recentemente, com o objetivo de manter as condições ambientais e termos medidas próximas das condições reais, diversos equipamentos foram desenvolvidos para realizarem medidas in situ. Entre os equipamentos mais comuns estão aqueles que realizam medidas de velocidade da onda acústica no sedimento, medidas geotécnicas e medidas de consumo de oxigênio pela biota. As medidas de velocidade do som e geotécnicas são realizadas com uma sonda com diversos sensores que são enterrados no fundo marinho e sendo os dados armazenados em

\begin{tabular}{|c|c|c|c|c|}
\hline Equipamento & Volume (litros) & Peso (kilos) & Limite Máximo de Prof. m & Tipo de Sedimento \\
\hline Armadilha tubular de sedimento & $0.5-1$ & 2 & 20 & Areia e lama \\
\hline Armadilha temporizada de sedimento & 12 ou $24 \times 0.2$ & 300 & 6000 & Lama \\
\hline
\end{tabular}

Tabela 4 - Características principais dos amostradores de sedimento em suspensão. 
memória no próprio equipamento(Davis, 1996, Davis, et al., 1996). As medidas biológicas são realizadas dentro de uma câmara enterrada no sedimento para isolar o meio circundante. Dentro da câmara, medidas são feitas com micro-sondas para determinar o consumo de oxigênio e temperatura, à medida que o tempo passa e a diversas alturas do fundo e também dentro do sedimento (Glud, et al., 1995).

\section{CONSIDERAÇÕES FINAIS}

A amostragem do fundo marinho envolve desafios e criatividade e quando é realizada com sucesso, a amostra representa o início de um processo. "Dê-me uma amostra do fundo oceânico e eu lhe contarei sua história". Esta é uma frase que revela a importância da amostragem geológica e o espírito investigativo que devemos ter a partir da sua análise.

A amostragem geológica do fundo marinho permite o contato direto entre o investigador e o sedimento de fundo, possibilitando uma análise detalhada de diversos parâmetros. Todavia é fundamental que o equipamento de amostragem seja apropriado para o tipo de sedimento e análise que se pretende realizar. Além disso, a amostra deve ser representativa do depósito sob investigação.

\section{REFERÊNCIAS}

DAVIS, A.M., 1996. Geophysics in offshore site investigation: a review of the state of the art. In: Geology of Siliciclastic Shelf Seas (Eds. De Batist, M. \& Jacobs, P.) Geological Society Special Publication v. 117, p. 323-338.

DAVIS, A.M., HUWS, D.G. \& HAYNES, R., 1996. Geophysical ground-truthing experiments in Eckernförde Bay. Geo-marine Letters, v. 16, p. 160-166.

ELLIS, J. P., 1973. Report on a new underway sediment sampler. Woods Hole, Mass. WHOI, $30 \mathrm{pp}$.
EMERY, K. O. \& CHAMPION, A. R., 1948. Underway bottom sampler. Jour. Sed. Petrology, v. 18, p. $30-33$.

GLUD, R.N.; GUNDERSEN， J.K.; REVSBECH, N.P.; JØRGENSEN, B.B.; HÜTTEL, M., 1995. Calibration and performance of the stirred flux chamber from the benthic lander ELINOR. Deep-Sea Res., v. 42, p. 1029-1042.

HVORSLEV, M. J. \& STETSON, H. C., 1946. Free-fall coring tube; a new gravity bottom sampler. Bull. Geol. Soc. Amer., v. 57, p. 935950.

KOWSMANN, R. O., COSTA, M. P. A., PALMA, J. J. C., VICALVI, M. A., 1983. Métodos de coleta e análise de sedimentos inconsolidados. In: Chaves, H A F (ed.) Processos e métodos (relatório final) Série Projeto REMAC, n. 6, p. 63-76.

KULLENBERG. B., 1947. The piston corer sampler. Svenska Hydrog. Biol. Komm. Skr. S. 3, Bd. 1, H. 2, 46pp.

LA FOND, E. C. \& DIETZ, R. S.,1948. New snapper type sea floor sampler. Jour. Sed. Petrology, v. 18, p.34-37.

LANESKY, D.E., LOGAN, B.W., BROWN, R.G. \& RINE, A.C., 1979. A new approach to portable vibracoring underwater and on land. Jour. Sed. Petrology, v. 48, p. 654-657.

MOORE, D.G., 1961. The free-corer; sediment sampling without wire and winch. Jour. Sed. Petrology. v. 31; n. 4, p. 627-630.

REINECK, H. E., 1963. Der Kastengreifer. Natur und Museum v. 93, p. 65-68.

SILVA, A. \& HOLLISTER, C. D., 1973. Geotechnical properties of ocean sediments recovered with Giant Piston corer, in Gulf of Maine. J. Geophys. Res., v. 78, p. 3597-3616.

ZEMBRUSCKI, S.G. \& FELIPE, J. R. C., 1978. Técnicas de dragagem no Cruzeiro Platôs Marginais do Nordeste Brasileiro. Bol. Téc. Petrobrás, Rio de Janeiro, v. 21, no. 3, p. 201234.

\section{NOTE ABOUT THE AUTHORS}

Ver página 326 